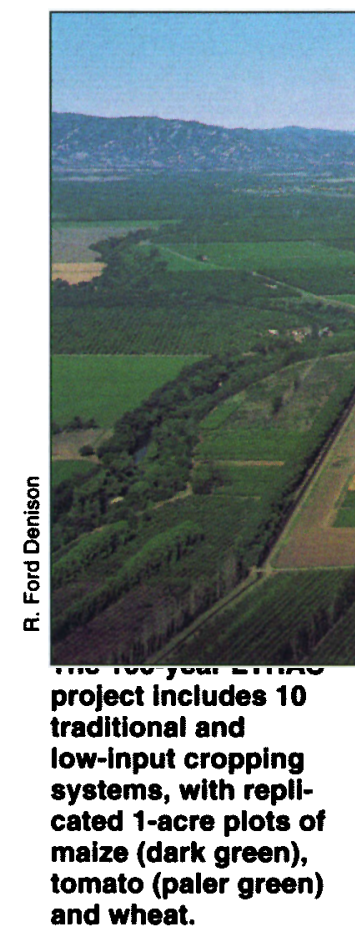

age weeds and pests with fewer pesticides,"

Temple says. "We also developed a clearer understanding of the economic opportunities and limitations to organic farming practices."

For example, weed control can be a challenge without herbicides.

"We've tried mulches, flaming, acetic acid, even geese in wet years when El Niño made it too difficult to get into fields," says Tom Lanini, UC Davis weed specialist. Buried drip irrigation is expensive $-\$ 600$ to $\$ 700$ per acre - but the extra expense to avoid wetting the soil surface where weeds grow could be justified in highvalue crops like tomatoes.

The SAFS Project is a collaborative effort involving UC Cooperative Extension farm advisors and specialists, campus-based scientists and growers.

The primary objective is to compare systems performance with respect to (1) abundance and diversity of weed, pathogen, arthropod and nematode populations; (2) differences in soil biology, physical and chemical properties and water relations; (3) crop growth, yield and quality; and (4) economic viability.

"After this season, we plan to retool and modify the project into a farming systems experiment focused on conservation tillage," says Temple.

For more information, see the SAFS Web site: http://agronomy.ucdavis.edu/safs/

\section{- Scientists study farm over century}

Even the 12-year Sustainable Agriculture Farming Systems (SAFS) Project seems short term compared to the UC Davis Long Term Research on Agricultural Systems (LTRAS) project. A 100 -year experiment occupies about one-third of the 300-acre LTRAS site.
While the primary objective of SAFS has been to test cropping systems that require less fertilizer and pesticides, LTRAS scientists focus on water, weeds, and threats to sustainability that may only be detectable over decades.

"Short-term trends can be poor predictors of sustainability," explains R. Ford Denison, director of LTRAS. At the Rothamsted Experiment Station, in England, yields in one system increased for 40 years, then decreased to near zero over the next few decades. Many soil properties that determine crop yield and control nitrate leaching change over decades rather than years. Organic matter doubled in another system at Rothamsted, but it took almost 100 years. At LTRAS, 2000 was the first year that water used by cover crops had an adverse effect on following crops; nitrogen-fixing weeds outcompeted other weed species in unfertilized control plots; and disease caused significant losses in some wheat systems. "We don't know yet whether these results represent the beginning of longterm trends," Denison says.

Researchers at LTRAS are attempting to learn the relationship between sustainability and external inputs. The 10 cropping systems differ mainly in how much irrigation water (which may become increasingly scarce in California) or nitrogen fertilizer is used (if any).

The scientists characterized soil conditions before the experiment began and collected "time-zero" archival samples from the 1-acre plots before planting wheat and cover crops in fall 1993.

One system follows organic guidelines and several include nitrogen-fixing legume cover crops. Sustainability will be determined from long-term trends in yield, profitability, efficiency in use of limited resources (such as water or energy), and environmental impact, such as leaching of nitrate or pesticides. Scientists are monitoring trends in key soil properties, such as organic matter, weed seeds, $\mathrm{pH}$ and salinity to see whether any of these are good predictors for long-term sustainability.

While acting as an "early warning system" to detect gradual but potentially harmful longterm trends, the project can make important short-term contributions to agriculture. "Inexpensive methods developed at LTRAS to obtain the data needed for precision farming have already been applied in on-farm research," Denison says.

For more information, see the LTRAS Web site: http://LTRAS.ucdavis.edu 